\title{
BMJ Open Sepsis in patients with haematological versus solid cancer: a retrospective cohort study
}

\author{
Ralphe Bou Chebl, ${ }^{1}$ Rawan Safa, ${ }^{1}$ Mohammad Sabra, ${ }^{1}$ Ali Chami, ${ }^{1}$ \\ Iskandar Berbari, ${ }^{1}$ Sarah Jamali, ${ }^{1}$ Maha Makki, ${ }^{1}$ Hani Tamim, ${ }^{2}$ \\ Gilbert Abou Dagher (D) ${ }^{1}$
}

To cite: Bou Chebl R, Safa R, Sabra M, et al. Sepsis in patients with haematological versus solid cancer: a retrospective cohort study. BMJ Open 2021;11:e038349. doi:10.1136/ bmjopen-2020-038349

- Prepublication history for this paper is available online. To view these files, please visit the journal online (http://dx.doi. org/10.1136/bmjopen-2020038349).

Received 09 March 2020 Revised 07 November 2020 Accepted 10 November 2020

Check for updates

(c) Author(s) (or their employer(s)) 2021. Re-use permitted under CC BY-NC. No commercial re-use. See rights and permissions. Published by BMJ.

${ }^{1}$ Department of Emergency Medicine, American University of Beirut Medical Center, Beirut, Lebanon

${ }^{2}$ Department of Internal Medicine, American University of Beirut Medical Center, Beirut, Lebanon

Correspondence to Dr Gilbert Abou Dagher; ga66@aub.edu.Ib

\section{ABSTRACT}

Objectives This study aims to examine the outcome of haematological and patients with solid cancer presenting with sepsis to the emergency department (ED).

Design Single-centred, retrospective cohort study. Setting conducted at an academic emergency department of a tertiary hospital.

Participants All patients $>18$ years of age admitted with sepsis were included.

Interventions Patients were stratified into two groups: haematological and solid malignancy.

Primary and secondary outcome The primary outcome of the study was in-hospital mortality. Secondary outcomes included intensive care unit (ICU) mortality, ICU and hospital lengths of stay and mechanical ventilation duration.

Results 442 sepsis cancer patients were included in the study, of which 305 patients $(69 \%)$ had solid tumours and 137 patients $(31 \%)$ had a haematological malignancy. The mean age at presentation was $67.92( \pm 13.32)$ and $55.37( \pm 20.85)(p<0.001)$ for solid and liquid tumours, respectively. Among patients with solid malignancies, lung cancer was the most common source (15.6\%). As for the laboratory workup, septic solid cancer patients were found to have a higher white blood count (12576.90 vs $9137.23 ; p=0.026$ ). During their hospital stay, a total of $158(51.8 \%)$ patients with a solid malignancy died compared with $57(41.6 \%)$ patients with a haematological malignancy $(p=0.047)$. There was no statistically significant association between cancer type and hospital mortality (OR 1.15 for liquid cancer $p$ 0.58). There was also no statistically significant difference regarding intravenous fluid administration, vasopressor use, steroid use or intubation.

Conclusion Solid tumour patients with sepsis or septic shock are at the same risk of mortality as patients with haematological tumours. However, haematological malignancy patients admitted with sepsis or septic shock have higher rates of bacteraemia.

\section{BACKGROUND}

Cancer is the leading cause of death worldwide. In the USA, there were an estimated 1685210 new cancer cases diagnosed in 2016. ${ }^{2}$ Oncology patients are considered a high-risk patient population, especially with
Strengths and limitations of this study

- Study looking at the outcome of haematological and patients with solid cancer presenting with sepsis to the emergency department.

- The most common infection sites in the solid tumour group were the lung, urinary tract and the gastrointestinal tract, whereas the most common sites in the haematological group were the blood, followed by the lung and urinary tract.

- There was no statistical difference in the association between cancer type and mortality (OR 1.15 for liquid cancer $\mathrm{p}$ 0.58)

- Haematological malignancy patients have higher rates of bacteraemia.

- This retrospective study is limited by its small sample size which could explain why several of our results were not statistically significant.

the higher risk of sepsis, most likely due to their immunosuppressed state. ${ }^{1}$ Susceptibility to infections is related to the host's ability to reconstitute their immune system following treatment. ${ }^{1}$ The longer it takes a patient to recover, the more at risk they are of developing an infection ${ }^{1}$ According to a study by Angus $e t$ al one in six patients presenting with severe sepsis had a malignancy. ${ }^{3}$

Sepsis has been implicated in approximately $15 \%$ of all patient with cancer admissions to the intensive care unit (ICU) with mortality rates found to be as elevated as $42 \%$ in sepsis and $53.4 \%$ in septic shock. ${ }^{4-6}$ Furthermore, cancer-related sepsis has been linked to an absolute increase in in-hospital mortality from $2.2 \%$ to $15.2 \% .^{7}$ It is important to note that the cancer population is heterogeneous and that there are important differences in comorbidities, illness severity and outcomes between haematological and solid tumour patients. ${ }^{89}$ Moreover, Torres et al showed that mortality differs between different subgroups of sepsis cancer patients, ranging from $36 \%$ to $78 \%$. $^{6}$ Despite recent advances in cancer care, certain 
subgroups of bone marrow transplant recipients and solidtumour patients continue to have higher mortality rates. ${ }^{8}$ With elevated rates of ICU admissions, resource expenditure and severe impact on patients' quality of life, it is imperative to better characterise patient with cancer prognosis and differences in treatment parameters.

Several studies have looked at oncological patients presenting to the emergency department (ED) with sepsis or septic shock and compared them to cancer-free septic patients. ${ }^{10}$ Others have discussed the management of infections in patients with haematological malignancy as well as in solid tumour and possible factors that may increase their susceptibility to infections. ${ }^{11}{ }^{12}$ However, very few studies have discussed the management of infection differences in patients with solid versus haematological cancer when presenting with sepsis. This study aims to contribute to a better understanding of sepsis by exploring the differences between haematological and solid malignancies as well as its toll on in-hospital mortality in patients with cancer.

\section{METHODS}

\section{Study design and setting}

This is a single-centre retrospective cohort study conducted in an academic ED of a tertiary care centre. The American University of Beirut's institutional board review approval was obtained (BIO-2018-0108) and the chart review was conducted for all patients who presented to the ED between 1 January= 2017 and 30 June 2019. According to the Third International Consensus Definitions for Sepsis and Septic Shock (Sepsis-3), sepsis was defined as the presence of infection with signs of organ dysfunction, which is documented with a Sequential (Sepsis-related) Organ Failure Assessment score of 2 points or greater. Septic shock was defined as a vasopressor requirement to maintain a mean arterial pressure of $65 \mathrm{~mm} \mathrm{Hg}$ or greater, and a serum lactate level greater than $2 \mathrm{mmol} / \mathrm{L}(>18 \mathrm{mg} / \mathrm{dL})$ in the absence of hypovolaemia. ${ }^{13}$ Patients who were pregnant and patients presenting secondary to cardiac arrest or trauma were excluded from this study.

\section{Patient selection}

Patients were identified through the hospital's medical record system (Electronic Health Record) through their International Classificaiton of Diseases-9 (ICD-9) codes (International Statistical Classification of Diseases, Ninth Revision and Related Health Problems). At our institution, an ICD-9 code is assigned to all patients after revising all the diagnoses attributed throughout a patient's hospital stay, including those made by ED physicians, hospitalists and intensivists. All adult patients above the age of 18 with an ICD-9 diagnosis of sepsis (995.91) and septic shock (785.52) were included.

\section{COHORT DESCRIPTION}

\section{Patient and public involvement statement}

This is a retrospective chart review study and with that being said, patients were not involved in the study process. Regarding dissemination of the study results, our future management will be changed accordingly and more focused towards each cancer subgroup needs when presenting with sepsis.

\section{Data collection}

Variables collected from patient's electronic medical record included patient characteristics, vital signs on presentation to the ED, laboratory results, vasopressor use, steroid use, intubation within the first 24 and 48 hours, and intravenous fluid requirements in the first 6 and 24 hours. Admission disposition, lengths of stay in the ED, ICU, general practitioner unit (GPU) and the total hospital length of stay (LOS). Patients were stratified according to survival status and lengths of stay calculations were done for survivors only. Moreover, information on disposition and hospital mortality was collected from the medical record. The primary outcome was in-hospital mortality. Statistical analysis was performed using SPSS V.25.0 (IBM). The distributions of the continuous and categorical variables were presented as mean $\pm \mathrm{SD}$ and frequency (percentages), respectively, with all our data being normally distributed. The different parameters were stratified among solid and haematological malignancy patients. In the bivariate analysis, Student's t-test and Pearson's $\chi^{2}$ test were used to assess the significance of the statistical association between the independent variables (continuous and categorical) and hospital mortality; the dependent variable. Tests were interpreted at a significance level alpha $=0.05$. We also performed multivariable logistic regressions to adjust for potential confounders in the association between the cancer type and in-hospital mortality as well as the association between cancer type and LOS. All variables with statistical significance and variables with clinical significance were included in the analysis and are detailed in the table's footnote.

\section{RESULTS}

\section{Patient characteristics}

A total of 442 sepsis cancer patients were included in the study, of which 305 patients (69\%) had solid tumours and 137 patients (31\%) had a haematological malignancy. Characteristics of both categories of patients with cancer are shown in table 1 . The mean age at presentation was $67.92( \pm 13.32)$ and $55.37( \pm 20.85) \quad(\mathrm{p}<0.001)$ for solid and liquid tumours, respectively, and there were more female patients in the solid tumour group compared with the liquid tumour group ( $37.7 \%$ vs $29.2 \%$, $\mathrm{p}=0.083)$. There were more patients with hypertension $(51.1 \%$ vs $36.5 \%$; 0.004$)$ diabetes $(32.5 \%$ vs $29 \%$; 0.016$)$ and CAD (21\% vs $13.9 \%$; p 0.076) in the solid cancer group than in the liquid cancer cohort. The liquid tumour cohort had a higher percentage of patients actively taking granulocyte-colony-stimulating factor $(38.7 \%$ vs $13.8 \%$, $\mathrm{p}<0.001)$. The most common infection sites in the solid tumour group were the lung $(44.1 \%, \mathrm{p}=0.099)$, urinary tract $(22.1 \%, \mathrm{p}=0.410)$ and the gastrointestinal tract 
Table 1 Demographic characteristics of patients with cancer presenting to the emergency department with sepsis

\begin{tabular}{|c|c|c|c|c|}
\hline & & Solid tumours ( $N=305)$ & Liquid tumours $(\mathrm{N}=137)$ & $P$ value \\
\hline Age (mean $\pm S D)$ & & $(67.92 \pm 13.32)$ & $(55.37 \pm 20.85)$ & $<0.0001$ \\
\hline Gender & Male, n (\%) & $190(62.3)$ & $97(70.8)$ & 0.08 \\
\hline Smoking, n (\%) & & $36(14.6)$ & $16(14.2)$ & 0.92 \\
\hline Medical history & Chronic kidney disease, n (\%) & $40(13.3)$ & $18(13.2)$ & 0.98 \\
\hline & Dyslipidaemia, n (\%) & $62(20.3)$ & $21(15.3)$ & 0.21 \\
\hline & Heart failure, n (\%) & $86(30.1)$ & $38(30.2)$ & 0.99 \\
\hline & Atrial fibrillation, $\mathrm{n}(\%)$ & $34(11.1)$ & $13(9.5)$ & 0.6 \\
\hline & Coronary artery disease, $\mathrm{n}(\%)$ & $64(21.0)$ & $19(13.9)$ & 0.07 \\
\hline & COPD, n (\%) & $29(9.5)$ & $4(2.9)$ & 0.06 \\
\hline Site of infection & Bone, n (\%) & $0(0.0)$ & $1(0.8)$ & 0.31 \\
\hline & Peritoneum, n (\%) & $4(1.3)$ & $0(0.0)$ & 0.32 \\
\hline & Surgical site, n (\%) & $4(1.3)$ & $1(0.8)$ & 1 \\
\hline & Liver, n (\%) & $4(1.3)$ & $0(0.0)$ & 0.32 \\
\hline & Heart, n (\%) & $4(1.3)$ & $1(0.8)$ & 1 \\
\hline & Skin, n (\%) & $8(2.7)$ & $10(7.5)$ & 0.02 \\
\hline & Urine, n (\%) & $66(22.1)$ & $25(18.7)$ & 0.41 \\
\hline & Escherichia coli, n (\%) & $50(16.4)$ & $35(25.5)$ & 0.02 \\
\hline & Streptococcus species, n (\%) & $12(3.9)$ & $3(2.2)$ & 0.41 \\
\hline & Enterococcus species, $\mathrm{n}(\%)$ & $7(2.3)$ & $2(1.5)$ & 0.73 \\
\hline & Pseudomonas aeruginosa, n (\%) & $9(3.0)$ & $8(5.8)$ & 0.14 \\
\hline & Staphylococcus coagulase negative, $\mathrm{n}(\%)$ & $27(8.9)$ & $12(8.8)$ & 0.97 \\
\hline & Staphylococcus aureus, n (\%) & $5(1.6)$ & $3(2.2)$ & 0.71 \\
\hline & Proteus mirabilis, $\mathrm{n}(\%)$ & $4(1.3)$ & $0(0.0)$ & 0.32 \\
\hline & Acinetobacter baumani, n (\%) & $2(0.7)$ & $0(0.0)$ & 1 \\
\hline Bacteria urine, $n$ & Klebsiella pneumonia, n (\%) & $13(4.3)$ & $1(0.7)$ & 0.07 \\
\hline$(\%)$ & E. coli, $\mathrm{n}(\%)$ & $43(14.1)$ & $16(11.7)$ & 0.49 \\
\hline & Enterococcus species, n (\%) & 7 (2.3) & $1(0.7)$ & 0.44 \\
\hline & P. aeruginosa, $\mathrm{n}(\%)$ & $4(1.3)$ & $3(2.2)$ & 0.68 \\
\hline & S. aureus, n (\%) & $1(0.3)$ & $1(0.7)$ & 0.52 \\
\hline & P. mirabilis, $\mathrm{n}(\%)$ & $1(0.3)$ & $1(0.7)$ & 0.52 \\
\hline & A. baumani, n (\%) & $3(1.0)$ & $2(1.5)$ & 0.65 \\
\hline & On G-CSF, n (\%) & $42(13.8)$ & $53(38.7)$ & $<0.0001$ \\
\hline
\end{tabular}

COPD, Chronic obstructive pulmonary disease; G-CSF, granulocyte-colony stimulating factor; TIA, Transient ischemic attack. 
Table 2 Subtypes of haematological and patients with solid tumour presenting to the emergency department with sepsis

Oncology patients $(\mathrm{N}=442)$

\begin{tabular}{|c|c|c|c|}
\hline Total haematological tumours, n (\%) & Underwent BMT, n & & $28(6.3)$ \\
\hline & Leukaemia, n (\%) & Total & $80(18.1)$ \\
\hline & & ALL, $n(\%)$ & $23(5.2)$ \\
\hline & & CML, n (\%) & $1(0.2)$ \\
\hline & & CLL, n (\%) & $18(4.1)$ \\
\hline & Lymphoma, n (\%) & Hodgkin's, n (\%) & $10(2.3)$ \\
\hline & & Non-Hodgkin's, n (\%) & $29(6.6)$ \\
\hline & Multiple myeloma, & & $11(2.5)$ \\
\hline & Myelodysplasia, $n$ & & $7(1.6)$ \\
\hline Total solid tumours, n (\%) & Lung, n (\%) & & 69 (15.6) \\
\hline & Prostate, n (\%) & & $29(6.6)$ \\
\hline & Liver, n (\%) & & $8(1.8)$ \\
\hline & Gastric, n (\%) & & $15(3.4)$ \\
\hline & Cervical, n (\%) & & $2(0.5)$ \\
\hline & Bladder, n (\%) & & $16(3.6)$ \\
\hline & Colorectal, n (\%) & & $30(6.8)$ \\
\hline & Kidney, n (\%) & & $8(1.8)$ \\
\hline & Gallbladder, n (\%) & & $13(2.9)$ \\
\hline
\end{tabular}

ALL, acute lymphoblastic leukaemia; AML, acute myeloid leukaemia; BMT, bone marrow transplant; CLL, chronic lymphocytic leukaemia; CML, chronic myeloid leukaemia.

(20.1\%, $\mathrm{p}=0.286)$, whereas the most common sites in the haematological group were the blood $(41.4 \%, \mathrm{p}<0.001)$, followed by the lung $(35.6 \%, \mathrm{p}=0.099)$ and urinary tract $(18.7 \%, \mathrm{p}=0.410)$. The liquid tumour cohort had a higher percentage of Escherichia coli bacteraemia (25.5\% vs $16.4 \%, \mathrm{p}=0.024$ ).

\section{Tumor characteristics}

Among patients suffering from a haematological malignancy, 80 patients $(18.1 \%)$ suffered from leukaemia with acute myeloid leukaemia being the most common type. Among patients with lymphoma, non-Hodgkin's lymphoma was more common (6.6\%) than Hodgkin's $(2.3 \%)$. Among patients who had solid malignancy, lung cancer was the most common source $(15.6 \%)$. The tumour types and distributions are summarised in table 2.

Other total solid tumours include the following subtypes: vaginal, laryngeal, nasopharyngeal, melanoma, angiosarcoma, adrenal cancer, glioblastoma multiforme and carcinoid tumour.

\section{Vital signs and laboratory parameters}

There was a significant difference between both cohorts when we looked at vitals on presentation. Liquid tumour patients were more likely to have high grade temperature $\left(>38.5^{\circ} \mathrm{C}\right)(27.6 \%$ vs $14.3 \%$; p 0.001$)$ as well as a heart rate $>100 \mathrm{bpm}$ ( $75 \%$ vs $64 \%$; $\mathrm{p} 0.02$ ). As for the laboratory workup, septic solid cancer patients were found to have a higher white blood count ( 12.58 vs 9.14 ; $p$ value $=0.026$ ), a lower albumin level $(25.59 \mathrm{~g} / \mathrm{L}$ vs $29.45 \mathrm{~g} / \mathrm{L} ; \mathrm{p}=0.000)$, a lower $\mathrm{pH}(\mathrm{pH}=7.35$ vs $\mathrm{pH}=7.39$; $\mathrm{p}=0.026)$ than patients with liquid tumours. There were also significant differences in electrolytes between both cohorts. All the different vital signs and laboratory values are summarised in table 3.

\section{Sepsis diagnosis, resuscitation parameters and patients' length of stay}

Sepsis treatment variables, LOS and outcomes of patients is present in table 4. During their hospital stay, a total of $158(51.8 \%)$ patients with a solid malignancy died 
Table 3 Vital signs and laboratory workup of patients with cancer presenting to the emergency department with sepsis

\begin{tabular}{|c|c|c|c|}
\hline & Solid tumours $(\mathrm{N}=305)$ & Liquid tumours $(\mathrm{N}=137)$ & $P$ value \\
\hline Temperature $\left({ }^{\circ} \mathrm{C}\right),($ mean $\pm \mathrm{SD})$ & $(37.22 \pm 0.94)$ & $(37.72 \pm 1.14)$ & $<0.0001$ \\
\hline Temperature $\geq 38.5^{\circ} \mathrm{C}$ & $42(14.3)$ & $37(27.6)$ & 0.001 \\
\hline Heart rate (beats/min), (mean \pm SD) & $(109.29 \pm 23.25)$ & $(111.53 \pm 25.12)$ & 0.01 \\
\hline Heart rate $\geq 100$ & $194(64.0)$ & $102(75.0)$ & 0.02 \\
\hline Systolic blood pressure (SBP) (mm Hg), (mean \pm SD) & $(110.39 \pm 26.45)$ & $(114.56 \pm 22.43)$ & 0.09 \\
\hline Diastolic blood pressure (mm Hg), (mean \pm SD) & $(63.11 \pm 17.99)$ & $(62.59 \pm 15.82)$ & 0.77 \\
\hline Respiratory rate (breaths/min), (mean \pm SD) & $(22.99 \pm 6.54)$ & $(22.08 \pm 5.68)$ & 0.17 \\
\hline Oxygen saturation (\%), (mean \pm SD) & $(93.50 \pm 8.45)$ & $(95.52 \pm 6.76)$ & 0.02 \\
\hline Oxygen saturation $<90 \%$ & $58(19.3)$ & $17(12.9)$ & 0.11 \\
\hline \multicolumn{4}{|l|}{ qSOFA criteria } \\
\hline Altered mental status & $80(26.2)$ & $27(19.7)$ & 0.14 \\
\hline Respiratory rate $>22$ & $134(43.9)$ & $65(47.4)$ & 0.49 \\
\hline SBP $<100$ & $127(41.6)$ & $49(35.8)$ & 0.24 \\
\hline$\geq 2, \mathrm{n}(\%)$ & $108(35.4)$ & $41(29.9)$ & 0.26 \\
\hline Lactate at presentation $($ mean $\mathrm{SD})$ & $(3.81 \pm 2.82)$ & $(3.72 \pm 3.28)$ & 0.8 \\
\hline Albumin $($ mean $\pm S D)$ & $(25.59 \pm 6.06)$ & $(29.45 \pm 7.35)$ & 0 \\
\hline Glucose $($ mean $\pm S D)$ & $(147.47 \pm 71.03)$ & $(143.65 \pm 67.27)$ & 0.66 \\
\hline WCC (mean $\pm S D)$ & $(12.58 \pm 10.52)$ & $(9.14 .23 \pm 16.48)$ & 0.03 \\
\hline ANC $($ mean \pm SD) & $(10.67 \pm 9.25)$ & $(3.38 \pm 5.30)$ & $<0.0001$ \\
\hline Haemoglobin (mean \pm SD) & $(105.4 \pm 20.1)$ & $(95.7 \pm 20.9)$ & $<0.0001$ \\
\hline BUN (mean \pm SD) & $(36.21 \pm 26.13)$ & $(27.43 \pm 25.76)$ & $<0.0001$ \\
\hline Creatinine $($ mean $\pm S D)$ & $(1.61 \pm 1.44)$ & $(1.20 \pm 0.97)$ & $<0.0001$ \\
\hline Baseline creatinine (mean \pm SD) & $(2.08 \pm 0.92)$ & $(2.03 \pm 1.00)$ & 0.86 \\
\hline Sodium (mean $\pm S D)$ & $(134.15 \pm 6.26)$ & $(135.92 \pm 5.25)$ & 0.002 \\
\hline Bicarbonate (mean $\pm S D)$ & $(20.52 \pm 5.66)$ & $(22.16 \pm 4.90)$ & 0.002 \\
\hline Total bilirubin (mean \pm SD) & $(2.91 \pm 5.45)$ & $(0.83 \pm 0.67)$ & $<0.0001$ \\
\hline Troponin (mean \pm SD) & $(0.11 \pm 0.13)$ & $(0.08 \pm 0.08)$ & 0.48 \\
\hline INR (mean $\pm S D)$ & $(1.83 \pm 3.17)$ & $(1.68 \pm 1.16)$ & 0.71 \\
\hline $\mathrm{pH}$ arterial $($ mean $\pm \mathrm{SD})$ & $(7.35 \pm 0.91)$ & $(7.39 \pm 0.08)$ & 0.03 \\
\hline
\end{tabular}

Temperature in ${ }^{\circ} \mathrm{C}$, heart rate in beats/minute, SBP and diastolic blood pressure in $\mathrm{mm} \mathrm{Hg}$, respiratory rate in breaths/minute, oxygen saturation in $\%$, WCC in $\times 10^{9} / \mathrm{L}$, ANC in $\times 10^{9} / \mathrm{L}$, haemoglobin in $\mathrm{g} / \mathrm{L}$, haematocrit in $\%$, BUN, creatinine, phosphate, calcium, magnesium, total bilirubin in $\mathrm{mg} / \mathrm{dL}$.

Sodium, potassium, bicarbonate, chloride in mmol/L, PT and $\mathrm{PTT}$ in seconds, $\mathrm{PaCO}_{2}, \mathrm{PaO}_{2} / \mathrm{FiO} 2$ in $\mathrm{mm} \mathrm{Hg}$. ANC, absolute neutrophil count; BUN, blood urea nitrogen; INR, international normalised ratio; $\mathrm{PaCO}_{2}$, partial pressure of carbon dioxide; $\mathrm{PaO}_{2} / \mathrm{FiO}_{2}$, partial pressure of oxygen/ fraction of inspired oxygen; PT, prothrombin time; PTT, partial thromboplastin time; qSOFA, quick sepsis-related organ failure assessment; WCC, white cell count.

compared with $57(41.6 \%)$ patients with a haematological malignancy $(p=0.047)$. There was no statistically significant difference between the two cohorts regarding intravenous fluid administration, vasopressor use, steroid use or intubation. After adjusting for all confounders and variable, there was no statistical difference in the association between cancer type and mortality (OR 1.15 for

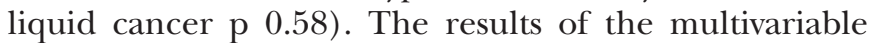
analysis are shown in table 5 . There was no statistically significant difference in GPU LOS between patients with haematological malignancy and patients with solid cancers (259.81 hours vs 161.85 hours; $\mathrm{p}=0.13$ ). There was also no statistically significant association between cancer type and LOS when we did the multivariable logistic regression ( $\beta 1.80,95 \% \mathrm{CI}-3.58$ to $7.19 ; \mathrm{p} 0.51)$. These results are summarised in table 6 .

\section{DISCUSSION}

The results of this study have shown that patients with solid malignancies have the same risk of mortality as haematological cancer patients when admitted to the hospital with sepsis. Although solid tumours make up the majority of cancers, the incidence of infection and bacteraemia 
Table 4 Sepsis treatment variables, LOS and outcomes of patients with cancer presenting to the ED with sepsis

Solid tumours $(\mathrm{N}=305)$ Liquid tumours $(\mathrm{N}=137)$ P value

\begin{tabular}{|c|c|c|c|c|}
\hline \multirow{2}{*}{$\begin{array}{l}\text { Intravenous fluid requirement } \\
\text { (mean } \pm S D)\end{array}$} & First 6 hours $($ mean $\pm S D)$ & $(2.53 \pm 1.85)$ & $(2.27 \pm 1.83)$ & 0.16 \\
\hline & First 24 hours (mean $\pm S D)$ & $(3.75 \pm 2.24)$ & $(3.61 \pm 2.32)$ & 0.57 \\
\hline \multirow[t]{5}{*}{ Vasopressor use in 24 hours } & & $90(29.5)$ & $41(29.9)$ & 0.91 \\
\hline & Norepinephrine, n (\%) & $87(28.5)$ & $40(29.2)$ & 0.88 \\
\hline & Dopamine, n (\%) & $5(1.6)$ & $3(2.2)$ & 0.71 \\
\hline & Dobutamine, $\mathrm{n}(\%)$ & $1(0.3)$ & $2(1.5)$ & 0.23 \\
\hline & Epinephrine, n (\%) & $8(2.6)$ & $2(1.5)$ & 0.73 \\
\hline Steroid use, n (\%) & & $66(21.7)$ & $39(28.5)$ & 0.11 \\
\hline Intubation in the first 24 hours & & $47(15.5)$ & $17(12.5)$ & 0.41 \\
\hline Intubation within the first 48 hours & & $31(10.2)$ & $14(10.3)$ & 0.97 \\
\hline ED LOS $($ mean $\pm S D)$ & & $(17.77 \pm 23.77)$ & $(15.99 \pm 28.17)$ & 0.49 \\
\hline $\begin{array}{l}\text { ED Disposition: admitted to hospital, } \\
\mathrm{n}(\%)\end{array}$ & & $298(97.7)$ & $137(100.0)$ & 0.24 \\
\hline \multicolumn{5}{|l|}{ Admission disposition } \\
\hline & GPU & $146(46.9)$ & $67(49)$ & 0.004 \\
\hline & $\mathrm{ICU}$ & $162(53.1)$ & $70(51)$ & 0.37 \\
\hline ICU LOS (mean \pm SD) & & $(212.04 \pm 370.81)$ & $(181.79 \pm 267.40)$ & 0.57 \\
\hline GPU LOS (mean \pm SD) & & $(161.85 \pm 285.73)$ & $(259.81 \pm 456.35)$ & 0.13 \\
\hline Total LOS $($ mean \pm SD) & & $(391.61 \pm 410.66)$ & $(462.56 \pm 511.67)$ & 0.3 \\
\hline Hospital mortality & & $158(51.8)$ & $57(41.6)$ & 0.05 \\
\hline \multirow[t]{3}{*}{ Disposition } & & & & 0.09 \\
\hline & Discharged home, n (\%) & $143(46.9)$ & $79(57.7)$ & \\
\hline & Other, n (\%) & $4(1.0)$ & $1(0.7)$ & \\
\hline
\end{tabular}

Intravenous fluid requirement in $\mathrm{mL} / \mathrm{kg}$, time to vasopressor use, time to initiation of antibiotics, ED LOS, ICU LOS, GPU LOS in hours. ED, emergency department; GPU, general practitioner unit; ICU, intensive care unit; LOS, length of stay.

is much less than in patients with haematological malignancies. ${ }^{14} 15$ In accordance with our results, Williams et al looked at the incidence of severe sepsis in haematological and solid tumours, and found it to be higher in haematological tumours but with similar mortality rates. ${ }^{5}$ Moreover, a study by Abou Dagher et al also found similar findings between haematological and solid tumour mortality, however, that study was limited by its sample size and the main objective was to compare the septic oncological population to the non-oncological population. ${ }^{10}$ Patients with cancer are at a higher risk of sepsisrelated mortality for several reasons. According to Oeyen et al the type of cancer the patient suffers from was found to be an important predictor of in-hospital mortality. ${ }^{89}$ In patients with solid cancer, many infections are related to the tumour itself, such as obstruction or disruption of normal anatomic barriers or surgical procedures related to the oncological disease. ${ }^{12}$ Whereas, haematological cancer patients are more likely to be immunocompromised, due to the higher severity of chemotherapythey receive. ${ }^{5}$ Despite this suppressed immune state, both cohorts had the same mortality, a finding which was also noted by Williams $e t a \tilde{l}$
It is important to note that there were no significant differences in the ED management regarding fluid resuscitation, vasopressor use, antibiotic initiation or intubation in either cohorts. This follows the trend of more aggressive protocol-based care of sepsis that was started in the non-oncologic population and has spilled over to oncological septic patient care. These protocols have evolved since early goal directed therapy and currently emphasise on early recognition and early antibiotics. ${ }^{16-19}$ Most institutions, as well as ours, follow a sepsis protocol that is applied to all patients. Febrile oncological patients are considered as high-risk patients in EDs and are readily and aggressively attended to. This might explain why survivors in both cohorts had similar hospital lengths of stay. Over the last couple of decades, sepsis-related mortality has been decreasing and patients who survive the disease are doing better and are leaving the hospital earlier. ${ }^{13}$

In our cohort, the predominating bacteria in the haematological cohort was E. coli. A study by Gedik et al described that Gram-negative bacteria predominated in neutropenic cancer patients, specially Enterobacteriacae. ${ }^{20}$ According to Savage et al myeloma patients with advanced disease are at risk for infection with 
Table 5 Multivariable logistic regression for in-hospital mortality

\begin{tabular}{|c|c|c|c|c|}
\hline & \multicolumn{4}{|c|}{ In-hospital mortality } \\
\hline & \multirow[b]{2}{*}{ OR } & \multicolumn{2}{|c|}{$95 \% \mathrm{Cl}$} & \multirow[b]{2}{*}{$P$ value } \\
\hline & & Lower & Upper & \\
\hline $\begin{array}{l}\text { Type of cancer- } \\
\text { liquid }\end{array}$ & 1.15 & 0.7 & 1.9 & 0.58 \\
\hline $\begin{array}{l}\text { Site of infection: } \\
\text { blood }\end{array}$ & 0.52 & 0.31 & 0.89 & 0.02 \\
\hline Site of infection: lung & 1.99 & 1.27 & 3.14 & 0.003 \\
\hline Temperature & 0.6 & 0.47 & 0.77 & $<0.0001$ \\
\hline BUN & 1.03 & 1.01 & 1.04 & $<0.0001$ \\
\hline Creatinine & 0.75 & 0.58 & 0.97 & 0.03 \\
\hline $\begin{array}{l}\text { Intubation in the first } \\
24 \text { hours }\end{array}$ & 3.61 & 1.75 & 7.44 & $<0.0001$ \\
\hline
\end{tabular}

Imposed: type of cancer (reference: solid).

Stepwise: age; gender (reference: male); coronary artery disease; hypertension; diabetes mellitus; COPD; skin; blood; lung; gallbladder; temperature; heart rate; oxygen saturation; WCC; ANC; haemoglobin; BUN; creatinine; bicarbonate; sodium; intravenous fluids in the first 6 hours; intubation inthe first 24 hours.

ANC, absolute neutrophil count; BUN, blood urea nitrogen; COPD, Chronic obstructive pulmonary disease; WCC, white cell count.

Gram-negative infections. ${ }^{21}$ This has also been shown by the IDSA's latest guidelines on treatment of neutropenic fever. The recommended antibiotic regimen is to provide coverage for gram negative bacteria as they are the more common bacterial isolates recovered..$^{22}$ Furthermore, in our cohort, the lung was the most common site of infection in our cohort. This could be due to several reasons. First of all, the lung functions as a gas exchange organ and is exposed to the external environment, as

Table 6 Multivariable linear regression for LOS ED

LOS ED

\begin{tabular}{lcccc}
\cline { 2 - 4 } & \multicolumn{3}{c}{$\mathbf{9 5 \%} \mathbf{~ C l}$} & \\
\cline { 3 - 4 } & $\boldsymbol{\beta}$ & Lower & Upper & P value \\
\hline Type of cancer-liquid & 1.8 & -3.58 & 7.19 & 0.51 \\
$\begin{array}{l}\text { Intravenous fluids in the } \\
\text { first 6hours }\end{array}$ & 3.75 & 2.44 & 5.07 & $<0.0001$ \\
Lung & & & & \\
Temperature & 7.37 & 2.49 & 12.26 & 0.003 \\
\hline
\end{tabular}

Imposed: type of cancer (reference: Solid).

Stepwise: age; gender (reference: male); coronaryartery disease; hypertension; diabetes mellitus; COPD; skin; blood; lung; gallbladder; temperature; heart rate; oxygen saturation; WCC; ANC; haemoglobin; BUN; creatinine ; bicarbonate; sodium; intravenous fluids in the first 6 hours; intubation in the first 24 hours.

ANC, absolute neutrophil count; BUN, blood urea nitrogen; COPD, Chronic obstructive pulmonary disease; ED, emergency department; LOS, length of stay; WCC, white cell count. well as infectious pathogens. Second of all, the lung is a very vascularised organ and as such, and haematogeneous seeding by bacteria can occur. ${ }^{23}$ Furthermore, postobstructive pneumonia is very common in patients with lung cancer and is thought to develop secondary to partial obstruction of an airway with overgrowth of bacteria distal to the obstruction. ${ }^{23}$

Blood cultures were significantly more positive in the haematological tumour cohort $(41.4 \%)$ than in the solid tumour cohort $(19.1 \%)$. This is probably due to the fact that haematological malignancies are at a higher risk of infections because of their rigorous chemotherapy and its cytotoxic effects on the gastrointestinal tract cells. ${ }^{16}$ Mayo and Wenzel also found that solid tumour patients had lower risk of bacteraemia than patients with haematological malignancies. ${ }^{15}$ Elting et al also reported that polymicrobial sepsis was 16 times less common per patient admission in patients with solid tumours than patients with acute leukaemia. ${ }^{14}$ Finally, it is important to note that patients in the solid tumour cohort were more likely to have chronic obstructive pulmonary disease (COPD) when compared with the haematological cohort $(9.5 \%$ vs $2.9 \%$ ). Chronic inflammation as well as the smoking associated with COPD is believed to play a role in lung cancer pathophysiology. ${ }^{24}$ COPD inflammation may result in repeated epithelial injury of the airway, with high cell turnover rates and DNA errors, resulting in amplified carcinogenic effect of smoking. ${ }^{25}$ However, further understanding of the interaction between cancer and these comorbidities may lead to better prevention, detection and safer treatment strategies. ${ }^{26}$

\section{Limitations}

There were several limitations to this study, First, this study was a retrospective chart review cohort study and thus has inherent limitations. The authors were aware of the potential biases, and to minimise them, frequent meetings were held between the principal investigator and data collectors to standardise the way how data was collected, entered and cleaned. Second, this study is limited by its small sample size which could explain why several of our results were not statistically significant. It was designed to detect a mortality difference between liquid and solid cancers. As such, all secondary analyses are exploratory and need further research to validate them. Furthermore, both cohorts were not matched in terms of comorbidities, as the patients with solid malignancies had more evidence of end organ damage and signs of a more severe sepsis. This could explain why there was an increased mortality seen on bivariate analysis. However, when we ran a multivariable analysis, we found that both cohorts have the same risk of mortality. Finally, the data was collected from a single centre, dealing with complex cases and referral cases which could explain our very high mortality in both cohorts and could limit the generalisability of these results. 


\section{CONCLUSION}

This study is one of the first studies looking at sepsis and septic shock in the complete cancer cohort as well as comparing characteristics, tumour characteristics, resuscitation parameters, LOS and mortality differences between patients with haematological and solid tumours. The study showed that patients with solid tumours with sepsis or septic shock, are at the same risk of mortality as patients with haematological tumours. However, patients with haematological malignancies with sepsis or septic shock have higher rates of bacteraemia. We hope that this study sheds light on this topic and how characteristics and outcomes of different tumour types may vary. We hope this stimulates further research on sepsis in this vulnerable patient population.

Contributors GAD, RBC and RS have made substantial contributions to conception and design of the study. RS, IB, MS, AC and SJ were involved in acquisition of data, data entry and data cleaning. MM and HT was involved in analysis and interpretation of data. RBC, GAD, RS and SJ have been involved in drafting the manuscript. RBC, GAD, HT and RS were involved in revising manuscript critically for important intellectual content. All authors contributed substantially to its revision. $\mathrm{GAD}$ and $\mathrm{RBC}$ take responsibility for the paper as a whole.

Funding The authors have not declared a specific grant for this research from any funding agency in the public, commercial or not-for-profit sectors.

Competing interests None declared.

Patient consent for publication Not required.

Ethics approval Approved by the Institutional Review Board of the American University of Beirut and the hospital's IRB (IRB \#BI0-2018-0108) and carried out in accordance with the recommendations provided. The research was performed according to ethical principles and in compliance with all prevailing and applicable laws, rules and regulations and policies regarding the protection of human subjects and research conduct as outlined by the declaration of Helsinki. Subject privacy and data confidentiality were of paramount concern at all times, and every effort was made to protect subjects' rights and welfare.

Provenance and peer review Not commissioned; externally peer reviewed.

Data availability statement Data are available on reasonable request.

Open access This is an open access article distributed in accordance with the Creative Commons Attribution Non Commercial (CC BY-NC 4.0) license, which permits others to distribute, remix, adapt, build upon this work non-commercially, and license their derivative works on different terms, provided the original work is properly cited, appropriate credit is given, any changes made indicated, and the use is non-commercial. See: http://creativecommons.org/licenses/by-nc/4.0/.

ORCID iD

Gilbert Abou Dagher http://orcid.org/0000-0002-9147-1515

\section{REFERENCES}

1 Babady NE. Laboratory diagnosis of infections in cancer patients: challenges and opportunities. J Clin Microbiol 2016;54:2635-46.

2 Arem H, Loftfield E. Cancer epidemiology: a survey of modifiable risk factors for prevention and survivorship. Am J Lifestyle Med 2018;12:200-10.
3 Angus DC, Linde-Zwirble WT, Lidicker J, et al. Epidemiology of severe sepsis in the United States: analysis of incidence, outcome, and associated costs of care. Crit Care Med 2001;29:1303-10.

4 Regazzoni CJ, Irrazabal C, Luna CM, et al. Cancer patients with septic shock: mortality predictors and neutropenia. Support Care Cancer 2004;12:833-9.

5 Williams MD, Braun LA, Cooper LM, et al. Hospitalized cancer patients with severe sepsis: analysis of incidence, mortality, and associated costs of care. Crit Care 2004;8:R291-8.

6 Torres VBL, Azevedo LCP, Silva UVA, et al. Sepsis-associated outcomes in critically ill patients with malignancies. Ann Am Thorac Soc 2015;12:150618124156002.

7 Hensley MK, Donnelly JP, Carlton EF, et al. Epidemiology and outcomes of cancer-related versus non-cancer-related sepsis hospitalizations. Crit Care Med 2019;47:1310-6.

8 Azoulay E, Soares M, Darmon M, et al. Intensive care of the cancer patient: recent achievements and remaining challenges. Ann Intensive Care 2011;1:5.

9 Oeyen SG, Benoit DD, Annemans L, et al. Long-term outcomes and quality of life in critically ill patients with hematological or solid malignancies: a single center study. Intensive Care Med 2013;39:889-98.

10 Abou Dagher G, El Khuri C, Chehadeh AA-H, et al. Are patients with cancer with sepsis and bacteraemia at a higher risk of mortality? A retrospective chart review of patients presenting to a tertiary care centre in Lebanon. BMJ Open 2017;7:e013502.

11 Freifeld AG, Bow EJ, Sepkowitz KA, et al. Clinical practice guideline for the use of antimicrobial agents in neutropenic patients with cancer: 2010 update by the infectious diseases society of america. Clin Infect Dis 2011;52:e56-93.

12 Rolston KVI. Infections in cancer patients with solid tumors: a review. Infect Dis Ther 2017;6:69-83.

13 Singer M, Deutschman CS, Seymour CW, et al. The third International consensus definitions for sepsis and septic shock (Sepsis-3). JAMA 2016;315:801-10.

14 Elting LS, Bodey GP, Fainstein V. Polymicrobial septicemia in the cancer patient. Medicine 1986;65:218-25.

15 Mayo JW, Wenzel RP. Rates of hospital-acquired bloodstream infections in patients with specific malignancy. Cancer 1982;50:187-90.

16 Lucas AJ, Olin JL, Coleman MD. Management and preventive measures for febrile neutropenia. P T 2018;43:228-32.

17 ProCESS Investigators, Yealy DM, Kellum JA, et al. A randomized trial of protocol-based care for early septic shock. N Engl J Med 2014;370:1683-93.

18 ARISE Investigators, ANZICS Clinical Trials Group, Peake SL, et al. Goal-Directed resuscitation for patients with early septic shock. $N$ Engl J Med 2014;371:1496-506.

19 Mouncey PR, Osborn TM, Power GS, et al. Trial of early, goal-directed resuscitation for septic shock. N Engl J Med 2015;372:1301-11

20 Gedik H, Simșek F, Kantürk A, et al. Bloodstream infections in patients with hematological malignancies: which is more fatal - cancer or resistant pathogens? Ther Clin Risk Manag 2014;10:743-52.

21 Savage DG, Lindenbaum J, Garrett TJ. Biphasic pattern of bacterial infection in multiple myeloma. Ann Intern Med 1982;96:47-50.

22 Freifeld AG, Bow EJ, Sepkowitz KA, et al. Clinical practice guideline for the use of antimicrobial agents in neutropenic patients with cancer: 2010 update by the infectious diseases Society of America. Clin Infect Dis 2011:52:e56-93.

23 Perlman LV, Lerner E, D'Esopo N. Clinical classification and analysis of 97 cases of lung abscess. Am Rev Respir Dis 1969;99:390-8.

24 Raviv S, Hawkins KA, DeCamp MM, et al. Lung cancer in chronic obstructive pulmonary disease: enhancing surgical options and outcomes. Am J Respir Crit Care Med 2011;183:1138-46.

25 Malkinson AM. Role of inflammation in mouse lung tumorigenesis: a review. Exp Lung Res 2005;31:57-82.

26 Koene RJ, Prizment AE, Blaes A, et al. Shared risk factors in cardiovascular disease and cancer. Circulation 2016;133:1104-14. 